\title{
Don Lindberg: Helping Others Thrive
}

\author{
Amy LINDBERG ${ }^{1}$ \\ La Grande, OR.
}

Keywords: Donald A.B. Lindberg M.D., leadership

Donald A.B. Lindberg M.D.'s ability to find another's strengths was terrific. When he saw them, he let you progress.

Dr. Lindberg (my father-in-law, whom I called 'papa') liked to see people succeed no matter the size of the accomplishment.

Here is a brief account of what occurred on a boat trip to Florida when he discovered I had a good sense of direction and became the family's vessel navigator.

Before a planned family boat trip from Virginia to Florida, Papa sent a set of waterway charts so I would have an understanding of where and how we were going. I was used to reading road maps but not charts. He let me highlight the channels we would follow. While he was not sure the latter was necessary, I convinced him it would help. He later agreed that, indeed, it was helpful at a glance to see where on the chart we were located.

On the first night of the trip, we needed to find an intended destination-marina. It was hard to read the shoreline from our position in the Chesapeake Bay and a fastapproaching dusk. Papa perceived we needed to be further south; I thought a little more to the north. Our GPS showed the course of where we had been, which in this case was a sloppy circle.

I said the spot with the most and brightest lights would likely be the marina. So, we headed that way and fortunately found it.

The next day we entered the harbor in Norfolk, VA. The first Inter Coastal Waterway marker set us off to the south. Once there, the options for the best channel to navigate were not obvious. Papa (aka 'the Captain') wanted to start over. Since I was sure I read the markers correctly, I responded we should stay the course.

However, the Captain proclaimed "start over." So, we redid some steps - and ended back at the same spot.

"Okay," he said, "you were right." Looking at the chart and finding our channel, we continued - and so it remained for the rest of the trip. From then on, I was the navigator and Papa, the Captain.

The story suggests Dr. Lindberg did not need to shoulder all of the limelight. He was very encouraging of others to find their sweet spot and make the best of their efforts. Ultimately, he wanted us to discover what we do well and thrive.

\footnotetext{
${ }^{1}$ Corresponding author: lindberg.amy@gmail.com
} 